\title{
Correspondence
}

\section{Why Even the Logic of Re-Defined Choice May Still Contradict the Logic of Care in Public Health Systems?}

\author{
Marianna Fotaki* \\ Warwick Business School, University of Warwick, Coventry, UK \\ Received: 17 September 2013, Accepted: 24 September 2013, ePublished: 29 September 2013
}

$\mathrm{I}$ would like to thank Dr. Benjamin Ewert (1) for his commentary on my short paper 'Is patient choice the future of health care systems?' (2) for three reasons. First, because I take heart from his support for my key thesis about the need to replace simplistic economic constructs underlying policy assumptions to explain how patients make health-related decisions in real life. Second, because it gives me the opportunity to, on the one hand, clarify my arguments on how health users' embeddedness in social relations and patients' multiple identities and personal circumstances influence these decisions; and to elaborate on the role of trust in this processes in more detail on the other hand. Third, because Dr. Ewert's contribution helped me re-think issues concerning the importance of patient choice in the context of new challenges that public health systems face such as the threat to free and universal provision of health care services. Although I fully agree with the rejection of the obsolete conception of choice that tends to dominate current policy debates, I do believe that his conviction concerning the inescapability of choice requires some further qualifications. This stems from the recognition of users expressed desire to trade off choice against other more important attributes of health care which have to do with their values and norms originating in the ethics of care, and which makes provision of health services possible.

Let me now explicate in brief these three points of agreement before presenting my ultimate disclaimer in the conclusion of this response to Dr. Ewert's comment. On the first point concerning the inadequacy of economic models as a guide for public health policy, without repeating the arguments expressed eloquently in the commentary, I would like to reiterate that these are at odds with reality because a simple notion of preference which underlies the idea of consumerist choice fails to account for the host of factors guiding patients' choices to explain the rationale, processes and outcomes of decision making in health care. Specifically, it ignores how patient's beliefs, cultural values, expectations, personal characteristics such as gender, age and the severity of medical condition could limit their ability or willingness to make choices (3). The instrumental and intrinsic value of choice in health services is potentially significant for all patients.

However, the asymmetry of access to resources, social capital and information is likely to lead to inequalities how choice is enacted. The recent Eurobarometer study examining patients' involvement across the EU found that users' desire for a more balanced relationship with their doctors is particularly true for younger well-educated patients, those with chronic conditions, and geographically is more prevalent in Western Europe (4).

The second and related problem of the narrative of knowledgeable users of public health services enacting their preferences via acts of consumption is that it overlooks their need for trustworthy relationships when they feel frail and vulnerable. Yet interpersonal and embodied trust, which is cultivated through a patient-doctor relationship, not only continues to be crucially important but patients are often prepared to trade off choice for trust (5). This is not merely because they lack appropriate information to make choices but because their need for medical professionals they can trust overrides their desire for 'shopping around'. The third point is about the necessity to re-define choice in the context of patientdoctor relationships where emotions and embodied experience of care are both resources used to inform patients' decisions that Dr. Ewert has aptly termed 'the relational choice'. Such an expanded 'emotionally intelligent' notion of choice is important for understanding how it works on the micro-level. However, the full extent of the meaning that choice has in health care must be considered in the context of values and the ethics of care. Retaining the public and universal aspects of the health system (6) is another important concern overriding patients' desire for choice. For instance, when ranked on a scale of one to five, fairness of public services comes first whilst choice and personalization of services is the last priority for the majority of the British population in a recent survey (7). This is unsurprising because the universal, free public health systems embody ethics of care that aim to make dependence on the stranger possible and tolerable, on a systemic level.

To conclude, the trade-offs between choice and other important health care attributes sketched above are real, particularly when considered in light of the multiple challenges (e.g. demographic, technological, raising expectations and others), which put the financial viability of public health systems in question. Apart from the necessity to develop a more nuanced understanding of how users of services make decisions in the context of health care 
which is predominantly about non-market choice, policy makers should take seriously into account their expressed priorities with regard to choice. Choice is, and always has been, an irreducible aspect of health provision involving decisions with profound implications for our well-being that start with whether, when and what services we access. Presenting patients with the idea of the inescapable choice as 'novelty' is beyond the point. Offering patients' choices that matter to them including the option 'not to choose' if they wish so, instead brings them closer to a true democratic governance of their health care system.

Ethical issues

Not applicable.

Competing interests

The Author declares that she has no competing interests.

Author's contribution

MF is the single author of the manuscript.

\section{References}

1. Ewert B. Patient choice has become the standard practice in healthcare provision: It is time to extend its meaning. International Journal of Health Policy and Management 2013; 1: 227-8.

2. Fotaki M. Is patient choice the future of health care systems? International Journal of Health Policy and Management 2013; 1: 121-3.

3. Fotaki M, Roland M, Boyd A, McDonald R, Smith L. What benefits will choice bring to patients? Literature review and assessment of implications. J Health Serv Res Policy 2008; 13: 178-84.

4. Eurobarometer. Eurobarometer qualitative study. Patient involvement: aggregate report. [updated 2012 May; cited 2013 Sep 12]. Available from: http://ec.europa.eu/public_opinion/archives/quali/ql_5937_patient_en.pdf

5. Goold SD. Trust, distrust and trustworthiness: lessons from the field. $J$ Gen Intern Med 2002; 17: 79-81.

6. Taylor-Gooby P, Wallace A. Public values and public trust: responses to welfare state reform in the UK. J Soc Policy 2009; 38: 401-19.

7. MORI I. What people want, need and expect from public services. London: 2020 Public Services Trust at RSA; 2010. 